Proc. of the International Conference on Mechanochemistry and Mechanical Alloying, Kraków, Poland, June 22-26, 2014

\title{
Mechanochemical Modification of V-Mo-Zr Oxide Compositions
}

\author{
S. Khalameida ${ }^{a}$, K. WieczoreK-Ciurowa ${ }^{b}$ And V. ZaZHigalov ${ }^{a, *}$ \\ ${ }^{a}$ Institute for Sorption and Problems of Endoecology, National Academy of Sciences of Ukraine, \\ 13, General Naumov St., 03-164 Kiev, Ukraine \\ ${ }^{b}$ Faculty of Chemical Engineering and Technology, Cracow University of Technology, \\ Warszawska 24, 31-155 Kraków, Poland
}

\begin{abstract}
The influence of mechanochemical treatment by high-energy ball milling in two media (water and ethanol) of different $\mathrm{V}_{2} \mathrm{O}_{5} / \mathrm{MoO}_{3} / \mathrm{ZrO}_{2}$ compositions on its structure modification and photocatalytic properties is considered. Milling process in both media leads to final products $\mathrm{Zr}\left(\mathrm{V}_{2} \mathrm{O}_{7}\right)$ and $\mathrm{Mo}_{4} \mathrm{~V}_{6} \mathrm{O}_{25}$. Their subsequent thermal treatment provides to formation of $\mathrm{Zr}\left(\mathrm{MoO}_{4}\right)_{2}$ and $\mathrm{V}_{2} \mathrm{MoO}_{8}$ composition. They show the photocatalytic activity in the dyes degradation process in aqueous solution.
\end{abstract}

DOI: 10.12693/APhysPolA.126.963

PACS: $81.20 . \mathrm{Ev}, 81.05 . \mathrm{Je}, 81.20 . \mathrm{Wk}$

\section{Introduction}

Vanadium-containing oxide compositions are versatile materials. For example, V-Mo-O system is known as a base of catalysts for partial oxidation or oxidative dehydrogenation $[1,2]$, the matrix for the electrode materials $[3-5]$, and gas sensors [6, 7]. Typically, such systems are prepared by calcining of the oxides in air or by evaporation of mixtures of ammonium salts solutions with subsequent their thermal decomposition. Recently, new approaches provide to complete interaction between reactants in order to exclude additional steps. These methods include mechanochemical activation (MChA) of solids. We have previously shown that the mechanochemical treatment of oxides' mixture $\left(\mathrm{V}_{2} \mathrm{O}_{5} / \mathrm{MoO}_{3}\right)$ and mixtures of oxides-salts $\left(\mathrm{V}_{2} \mathrm{O}_{5} /\left(\mathrm{NH}_{4}\right)_{2} \mathrm{Mo}_{2} \mathrm{O}_{7}\right)$ leads to their activation and improvement of catalytic properties in the mild oxidation processes of hydrocarbons [8-10] and photocatalytic properties [11].

In this work, the mechanochemical treatment of the ternary system $\mathrm{V}_{2} \mathrm{O}_{5}-\mathrm{MoO}_{3}-\mathrm{ZrO}_{2}$ was carried out modifying its physicochemical and photocatalytic properties. It is also known that these oxide compositions are promising catalysts to produce acrolein [12]. Therefore, the development of new techniques as alternative methods of synthesis of the multifunctional materials towards green chemistry is important.

\section{Experimental}

The objects of study are V-Mo-Zr oxide compositions as a mixture of non-porous low-dispersed crystalline oxides $\left(\mathrm{V}_{2} \mathrm{O}_{5}, \mathrm{MoO}_{3}\right.$, and $\left.\mathrm{ZrO}_{2}\right)$. The samples were

\footnotetext{
* corresponding author; e-mail: zazhigal@ispe.kiev.ua
}

prepared by thoroug grinding in an agate mortar components with different ratios (at.\%) V:Mo:Zr = 1:1:1, 1:1:2, $2: 1: 1$, and $1: 2: 1$. The resulting mixtures were subjected to mechanochemical treatment in a planetary mill Pulverissette 7 (Fritsch $\mathrm{GmbH}$ ) with balls of agate and rotation speed $700 \mathrm{rpm}$. The milling processes were performed in liquid media (water and ethanol) with time ranged from 30 to 60 min. Samples after high-energy ball milling were thermally treated for $3 \mathrm{~h}$ at a temperature of $400-500{ }^{\circ} \mathrm{C}$ (these temperatures were determined by DTA data).

The physicochemical characteristics of the samples were determined by means of the following methods: (i) X-ray powder diffraction (a diffractometer Philips Analyzer with $\mathrm{Cu} K_{\alpha}$ radiation), (ii) the specific surface area (SSA) of the samples was determined by the BrunauerEmmett-Teller (BET) method using nitrogen (Analyzer Quantachrome), (iii) the total pore volume $V_{\Sigma}$ was determined by water impregnation of samples, (iv) the thermal analysis (TG-DTA) were carried out using the Derivatograph Q-1500 system F. Paulik, J. Paulik, L. Erdey in the temperature range of $25-1000^{\circ} \mathrm{C}$ ). The electronic spectra of the samples were recorded by the spectrometer Lambda 35 UV-Vis.

The photocatalytic activity of samples was estimated in photodegradation reaction in Rhodamine $\mathrm{B}$ aqueous solution (concentration of the solution of Rhodamine $B$ was $\left.2 \times 10^{-5} \mathrm{~mol} / \mathrm{l}\right)$ under the action of ultraviolet and visible radiation.

\section{Results and discussion}

Figure 1 shows the XRD diffraction patterns for the initial oxides' mixtures with various ratios of components in the V-Mo-Zr-O system and after their mechanochemical treatment in ethanol and water for $30 \mathrm{~min}$. One can see that the partial amorphization of molybdenum and vanadium oxides takes place even during short milling time of vanadium, molybdenum and zirconium oxides' 

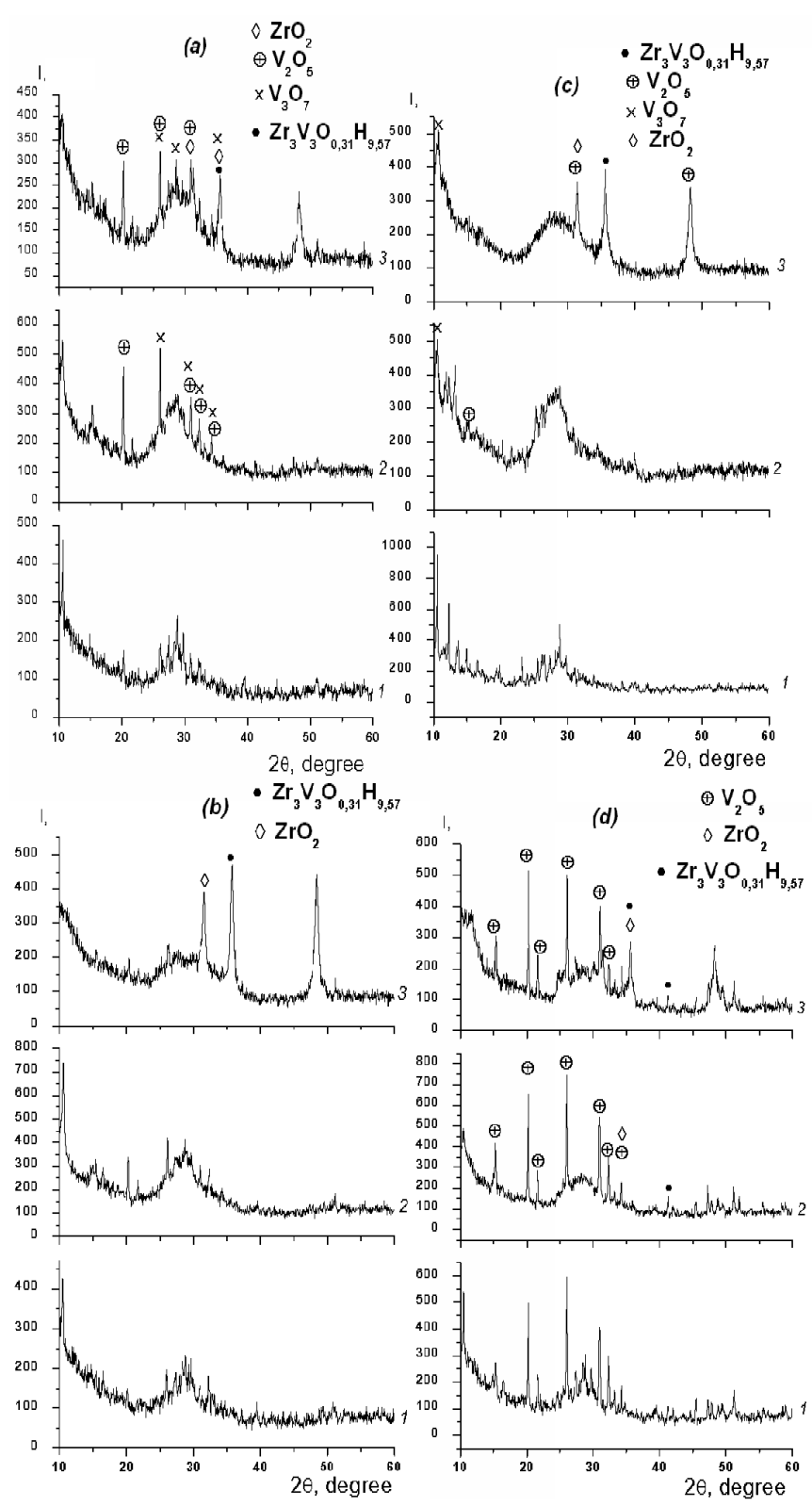

Fig. 1. X-ray diffractograms of $\mathrm{V}_{2} \mathrm{O}_{5} / \mathrm{MoO}_{3} / \mathrm{ZrO}_{2}$ samples: (1) for initial composition and (2) after MChA in ethanol and (3) in water. Ratio of $\mathrm{V}_{2} \mathrm{O}_{5} / \mathrm{MoO}_{3} / \mathrm{ZrO}_{2}$ : (a) $1 / 1 / 1$, (b) $1 / 1 / 2$, (c) $1 / 2 / 1$, (d) $2 / 1 / 1$.

mixtures, and new reflexes independently of applied medium (water, ethanol) appear. They correspond to new-formed polyvanadium acids $\mathrm{V}_{3} \mathrm{O}_{7} \cdot \mathrm{H}_{2} \mathrm{O}$. There are also present reflexes of unreacted oxides $\mathrm{V}_{2} \mathrm{O}_{5}$ and $\mathrm{ZrO}_{2}$. Mechanochemical treatment in water for 30 min resulting in the formation of $\mathrm{Zr}_{3} \mathrm{~V}_{3} \mathrm{O}_{0.31} \mathrm{H}_{9.57}$ phase. These results are in accordance with the mechanism proposed earlier for metal oxides which were mechanochemically activated in water [13]. This mechanism involves the process of water decomposition into hydroxyl radicals and atomic hydrogen and its action in reduction process of vanadium oxide. Thus, there is solid phase interaction between $\mathrm{V}_{2} \mathrm{O}_{5}$ and $\mathrm{ZrO}_{2}$ with the introduction of hydrogen into the newly formed phase, namely $\mathrm{Zr}_{3} \mathrm{~V}_{3} \mathrm{O}_{0.31} \mathrm{H}_{9.57}$, in this case.

Increase of mechanochemical treatment time to $60 \mathrm{~min}$ leads to destruction of $\mathrm{Zr}_{3} \mathrm{~V}_{3} \mathrm{O}_{0.31} \mathrm{H}_{9.57}$ and the appearance of known nonstoichiometric Magnelli phases, which are formed through the crystallographic shear mechanism. The mechanism of formation of crystallographic shear plane can be as follows: under the action of intense mechanical stress on the solid crystal structure ordering, removing the surface oxygen occurs, while oxygen vacancies are forming. With increase of concentration defects, they begin to occupy certain lattice sites.

The ordering the defect structure takes place, leads to the formation of nonstoichiometric phases Magnelli, that represent a crystal domain with another structure and composition.

The solid phase reactions between $\mathrm{V}_{2} \mathrm{O}_{5}$ with $\mathrm{ZrO}_{2}$ and $\mathrm{V}_{2} \mathrm{O}_{5}$ with $\mathrm{MoO}_{3}$ forming new compounds of $\mathrm{Zr}\left(\mathrm{V}_{2} \mathrm{O}_{7}\right)$ and $\mathrm{Mo}_{4} \mathrm{~V}_{6} \mathrm{O}_{25}$ are also observed, respectively (these XRD patterns are not shown).

Subsequent calcination of the obtained samples at 400 $500{ }^{\circ} \mathrm{C}$ (the temperature from the DTA curves) leads to re-oxidation processes in solids. As a result, oxides in the higher oxidation state of metals and molybdates with compositions $\mathrm{Zr}\left(\mathrm{MoO}_{4}\right)_{2}$ and $\mathrm{V}_{2} \mathrm{MoO}_{8}$ are formed. This is confirmed by XRD patterns (Fig. 2) and FTIR spectra (Fig. 3).

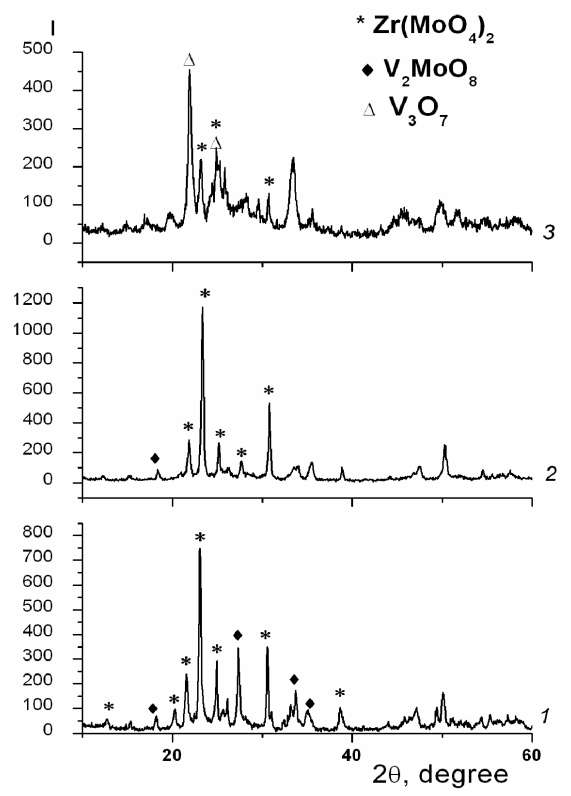

Fig. 2. X-ray diffractograms of $\mathrm{V}_{2} \mathrm{O}_{5} / \mathrm{MoO}_{3} / \mathrm{ZrO}_{2}$ samples with ratio of oxides $=1 / 1 / 1$ : (1) for initial composition after additional thermal treatment at $450{ }^{\circ} \mathrm{C}$, (2) after MChA in ethanol and the subsequent thermal treatment at $450{ }^{\circ} \mathrm{C}$ and (3) after $\mathrm{MchA}$ in water and further thermal treatment at $450{ }^{\circ} \mathrm{C}$. 


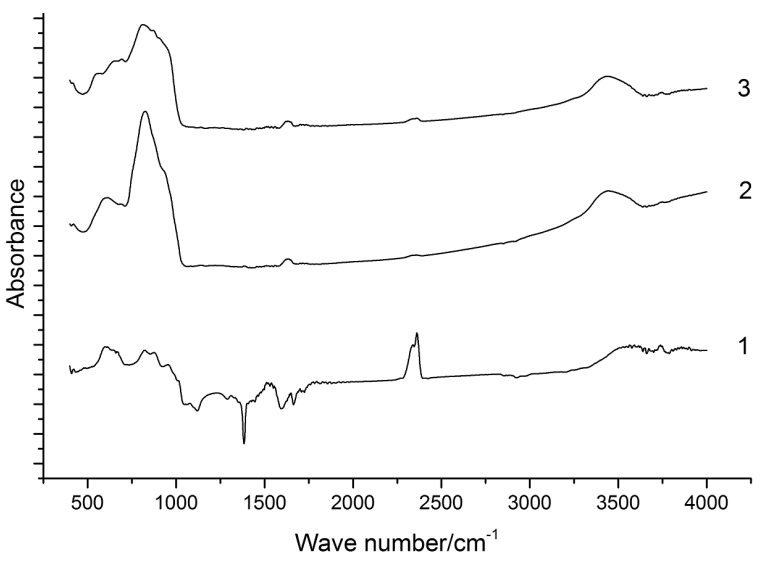

Fig. 3. FTIR spectra of $\mathrm{V}_{2} \mathrm{O}_{5} / \mathrm{MoO}_{3} / \mathrm{ZrO}_{2}$ samples with ratio of oxides $=1 / 1 / 1$ : (1) for initial composition after additional thermal treatment at $450{ }^{\circ} \mathrm{C}$, (2) after MchA in ethanol and the subsequent thermal treatment at $450{ }^{\circ} \mathrm{C}$ and (3) after MChA in water and further thermal treatment at $400{ }^{\circ} \mathrm{C}$.

Mechanochemical processing conditions and subsequent calcination parameters define the porous structure of intermediates and final oxides. Phase transitions occurring at these stages also have a decisive influence. Thus, the mechanochemical treatment in ethanol leads to appreciable increase in the specific surface area, whereas in the water, this value decreases (Table I).

TABLE I

Influence of mechanochemical treatment conditions on the selected properties of $\mathrm{V}_{2} \mathrm{O}_{5} / \mathrm{MoO}_{3} / \mathrm{ZrO}_{2}$ compositions; time of milling - $60 \mathrm{~min}$.

\begin{tabular}{c|c|c|c}
\hline $\begin{array}{c}\text { Composition } \\
\text { of sample }\end{array}$ & $\begin{array}{c}\text { MChA } \\
\text { medium }\end{array}$ & $\begin{array}{c}\text { SSA } \\
{\left[\mathrm{m}^{2} / \mathrm{g}\right]}\end{array}$ & $\begin{array}{c}V_{\Sigma} \\
{\left[\mathrm{cm}^{3} / \mathrm{g}\right]}\end{array}$ \\
\hline $\mathrm{V}_{2} \mathrm{O}_{5}$ & initial & 6 & n.d. \\
\hline $\mathrm{MoO}_{3}$ & initial & 2 & n.d. \\
\hline $\mathrm{ZrO}_{2}$ & initial & 120 & n.d. \\
\hline \multirow{2}{*}{$\mathrm{V} / \mathrm{Mo} / \mathrm{Zr}(1 / 1 / 1)$} & Ethanol & 20 & 0.43 \\
& Water & 3 & 0.40 \\
\hline \multirow{2}{*}{$\mathrm{V} / \mathrm{Mo} / \mathrm{Zr}(1 / 1 / 2)$} & Ethanol & 40 & 0.36 \\
& Water & 2 & 0.30 \\
\hline \multirow{2}{*}{$\mathrm{V} / \mathrm{Mo} / \mathrm{Zr}(1 / 2 / 1)$} & Ethanol & 18 & 0.42 \\
& Water & 2 & 0.50 \\
\hline \multirow{2}{*}{$\mathrm{V} / \mathrm{Mo} / \mathrm{Zr}(2 / 1 / 1)$} & Ethanol & 29 & 0.39 \\
& Water & 15 & 0.37 \\
\hline
\end{tabular}

n.d. - not determined

In the first case it is caused by the anisotropic destruction of crystals, in the second one - the collective recrystallization. It is important that the initial mixtures are oxide powders form but after mechanochemical treatment, both in water and in ethanol, they are converted to porous, namely meso-macroporous material with a total pore volume of $0.3-0.5 \mathrm{~cm}^{3} / \mathrm{g}$. Typically, due to the thermal treatment of milled samples, porosity increases.

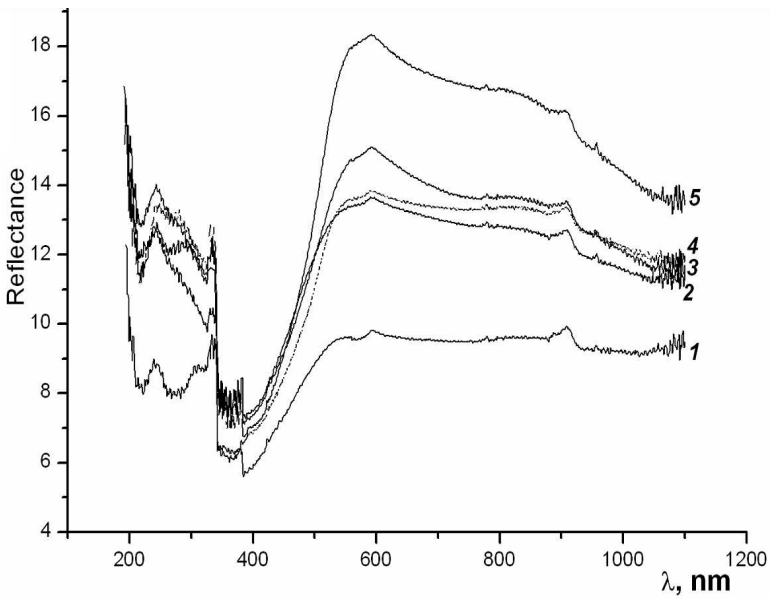

Fig. 4. UV-Vis spectra of samples $\mathrm{V}_{2} \mathrm{O}_{5} / \mathrm{MoO}_{3} / \mathrm{ZrO}_{2}$ compositions: (1) with a ratio $1 / 1 / 1$ after $\mathrm{MChA}$ in water and subsequent thermal treatment at $450{ }^{\circ} \mathrm{C},(2)$ with a ratio $1 / 1 / 1$ after $\mathrm{MChA}$ in ethanol and subsequent thermal treatment at $450{ }^{\circ} \mathrm{C}$, (3) with a ratio $2 / 1 / 1$ after $\mathrm{MChA}$ in ethanol and subsequent thermal treatment at $450{ }^{\circ} \mathrm{C},(4)$ with a ratio $1 / 2 / 1$ after $\mathrm{MChA}$ in ethanol and subsequent thermal treatment at $450^{\circ} \mathrm{C}$, (5) with a ratio $1 / 1 / 2$ after $\mathrm{MChA}$ in ethanol and subsequent thermal treatment at $500{ }^{\circ} \mathrm{C}$.

TABLE II

Photocatalytic properties of $\mathrm{V}_{2} \mathrm{O}_{5} / \mathrm{MoO}_{3} / \mathrm{ZrO}_{2}$ compositions mechanochemically activated under different conditions and subsequently thermally treated.

\begin{tabular}{c|c|c|c|c|c}
\hline \hline $\begin{array}{c}\mathrm{V}_{2} \mathrm{O}_{5} / \mathrm{MoO}_{3} / \mathrm{ZrO}_{2} \\
(\mathrm{ratio})\end{array}$ & $\begin{array}{c}\text { MChA } \\
\text { medium }\end{array}$ & $\begin{array}{c}T \\
{\left[{ }^{\circ} \mathrm{C}\right]}\end{array}$ & $\begin{array}{c}E_{g} \\
{[\mathrm{eV}]}\end{array}$ & $\begin{array}{c}K_{d}^{\mathrm{UV}} \\
{\left[10^{5} \mathrm{~s}^{-1}\right]}\end{array}$ & $\begin{array}{c}K_{d}^{\mathrm{VIS}} \\
{\left[10^{5} \mathrm{~s}^{-1}\right]}\end{array}$ \\
\hline$(1 / 1 / 1)$ & pure & - & 2.95 & 3.65 & 2.75 \\
$(1 / 1 / 1)$ & water & 450 & 2.42 & 4.85 & 3.6 \\
$(1 / 1 / 1)$ & ethanol & 450 & 2.47 & - & - \\
$(1 / 1 / 2)$ & ethanol & 500 & 2.34 & - & 3.3 \\
$(1 / 1 / 2)$ & ethanol & 500 & 2.35 & 6.2 & 2.5 \\
$(1 / 2 / 1)$ & ethanol & 500 & 2.35 & - & -
\end{tabular}

UV-Vis spectra of samples after mechanochemical activation and subsequent thermal treatment are shown in Fig. 4. Spectra of $\mathrm{V}_{2} \mathrm{O}_{5} / \mathrm{MoO}_{3} / \mathrm{ZrO}_{2}$ compositions contain an asymmetric band with maximum characteristic for vanadium oxide, as well as broad band in the region $>600 \mathrm{~nm}$ due to the presence of metals with a low oxidation state. It can be seen that the band gap $E_{\mathrm{g}}$ slightly decreases with enrichment of mixture the molybdenum and zirconium oxides, which have smaller values $E_{\mathrm{g}}$ than $\mathrm{V}_{2} \mathrm{O}_{5}[9,11]$.

There is also a blue shift of the absorption edge as a result of mechanochemical treatment of compositions. So, $E_{\mathrm{g}}$ is equal to 2.95 and $2.42-2.47 \mathrm{eV}$ for the initial and activated samples, respectively (Table II). Furthermore, all samples show a strong absorption in the visible region (its value depends on the ratio of $\mathrm{V}: \mathrm{Mo}: \mathrm{Zr}$ ). It 
should be added that a maximum of radiation from the lamp used for photocatalysis is $568 \mathrm{~nm}$. As a consequence, $\mathrm{V}_{2} \mathrm{O}_{5} / \mathrm{MoO}_{3} / \mathrm{ZrO}_{2}$ composition exhibits a sufficiently high photocatalytic activity in the degradation of rhodamine $\mathrm{B}$ in an aqueous medium under the influence of visible light (see Table II, column 4). At the same time, the degradation rate constant $K_{\mathrm{d}}$, calculated from the first order kinetic equation obtained for the photocatalytic reaction by UV irradiation, has higher values. It is important that the mechanochemical treatment leads to a substantial increase of photocatalytic activity of the oxides' compositions in comparison with starting mixtures (both in UV and visible region), as exemplified by the oxides, with a ratio of 1:1:1 (Table II).

Thus, modifying the $\mathrm{V}_{2} \mathrm{O}_{5} / \mathrm{MoO}_{3} / \mathrm{ZrO}_{2}$ compositions by mechanochemical treatment in water and ethanol changes the crystal structure, phase composition and the dispersity of the samples. Mechanochemical modification also promotes the change of electronic and spectral properties of the activated samples and as a result - increase in the photocatalytic activity of $\mathrm{V}_{2} \mathrm{O}_{5} / \mathrm{MoO}_{3} / \mathrm{ZrO}_{2}$ during degradation process of rhodamine $\mathrm{B}$ in aqueous solution.

\section{References}

[1] G. Centi, F. Cavani, F. Trifiro, Selective Oxidation by Heterogeneous Catalysis, Kluwer/Plenum, New York 2001.

[2] X. Gao, P. Ruiz, Q. Xin, X. Guo, B. Delmon, Catal. Lett. 23, 321 (1994).
[3] M. Eguchi, F. Maki, H.E. Kimura, K. Takahashi, Electrochemistry 68, 474 (2000).

[4] M. Liqiang, Y. Fan, Z. Yunlong, X. Xu, X. Bin, L. Yanzhu, L. Hangyu, Mater. Today 14, 346 (2011).

[5] N. Kosova, E. Devyatkina, Solid State Ionics 172, 181 (2004).

[6] K.V. Madhuri, B.S. Naidu, O.M. Hussain, Mater. Chem. Phys. 77, 22 (2002).

[7] Ch.V. Subba Reddy, I.-H. Yeo, S.-I. Mho, J. Phys. Chem. Solids 69, 1261 (2008).

[8] V.A. Zazhigalov, S.V. Khalameida, N.S. Litvin, I.V. Bacherikova, J. Stoch, L. Depero, Kinetics Catal. 49, 692 (2008).

[9] S. Khalameida, J. Skubiszewska-Zięba, V. Zazhigalov, R. Leboda, K. Wieczorek-Ciurowa, J. Therm. Anal. Calorim. 101, 823 (2010).

[10] E. Skwarek, S. Khalameida, W. Janusz, V. Sydorchuk, N. Konovalova, V. Zazhigalov, J. Skubiszewska-Zieba, R. Leboda, J. Therm. Anal. Calorim. 106, 881 (2011).

[11] V. Sydorchuk, S. Khalameida, V. Zazhigalov, O. Khanina, Chem. Phys. Technol. Surf. 4, 266 (2013) (in Ukrainian).

[12] X.D. Yi, H. Lin, Y.M. He, C.J. Huang, W.Z. Weng, H.L. Wan, Acta Phys. Chim. Sin. 20, 309 (2004).

[13] V.A. Zazhigalov, J. Haber, J. Stoch, A.I. Kharlamov, L.V. Bogutskaya, I.V. Bacherikova, A. Kowal, Solid State Ionics 101-103, 1257 (1997). 